Technical Advisors as Brokers : Translating Gender Equality and Human Rights Policies and Values into Practice in the Water Sector in Nepal

\title{
White, Pamela
}

2019-07

White , P \& Haapala , J 2019 , ' Technical Advisors as Brokers : Translating Gender Equality and Human Rights Policies and Values into Practice in the Water Sector in Nepal ', pÿEuropean Journal of Development Research , vol. 31 , no. 3 , pp. 643662 . https://doi.org/10.1057/s41287-018-0

http://hdl.handle.net/10138/321564

https://doi.org/10.1057/s41287-018-0173-0

unspecified

acceptedVersion

Downloaded from Helda, University of Helsinki institutional repository.

This is an electronic reprint of the original article.

This reprint may differ from the original in pagination and typographic detail.

Please cite the original version. 


\title{
TECHNICAL ADVISORS AS BROKERS: TRANSLATING GENDER EQUALITY AND HUMAN RIGHTS POLICIES AND VALUES INTO PRACTICE IN THE WATER SECTOR IN NEPAL
}

Pamela White and Juho Haapala

\begin{abstract}
How are development policies, prepared by donors, translated to practice in different social settings? Many modalities are used but we consider bilateral projects to be a conduit for value change and sustainable development. Our case concerns two bilateral projects with Nepali and international technical advisors. The article discusses the complex scenario technical advisors must tread to broker policy ideals into practice. They must respect the intentions and regulatory and normative frameworks of the donor and recipient governments, and the local cultures and realities of the local governments and villagers they work with. At the same time, they promote value change in support of gender equality and human rights. This also raises the question of whose values count - those of the donor, Nepalese Government, local participants or the advisors? We argue that technical assistance has an indispensable role in facilitating sustainable, equitable, and inclusive rural development outcomes in socio-culturally difficult operational environments.
\end{abstract}

Key Words: Development Cooperation; Technical Advisors; Gender Equality; Social Inclusion; Rural Water Supply; Human Rights; Nepal; Brokers 


\section{INTRODUCTION}

Our case concerns two bilateral projects involving Nepali and international technical advisors (TA). This article addresses the sometimes invisible role of TA, against their significance for implementation and intervention realities. In particular, we ask how the guidelines of development cooperation - outlined in countless documents and agreements (in this case Finnish and Nepali) - can be successfully applied?

Donors have expectations of what will be achieved with their money. These include explicit physical targets but often implicit changes in values. In any development context there will be a plethora of values - there are the official positions of the donor, the national government and line ministries, project and local government. Within each group are individuals, with their own life experiences, cultural and political standpoints, gender, caste, ethnicity and personality.

So another point of contention is 'whose values count'? Should the values and cultural norms of the most powerful members of the local community prevail, even if this limits the human rights of the disadvantaged and maintains the status quo? Or is it valid for a project, in the hands of TA, to take a stand and implement development policy? There has been little research on the bricolage processes involved at community level, and how projects could choose what aspects to emphasise and facilitate.

One of the key methods to provide technical assistance in bilateral development cooperation is to contract TA to work in projects (via consulting companies). Yet, there is little literature dealing with the specific experience and knowledge technical advisors need to turn policy into practice, and they are notably absent from the Finnish development policies and documents. One of our Finnish respondents joked that 'consultants are the bastard children of development - no one 
wants to acknowledge them!' (C4). In this article we consider the role that advisors play as brokers - finding a practical solution between the potentially divergent agendas of the donor and recipient governments, and water users on the ground.

We ask the question: What is the role the technical advisors play in the case study project implementation, particularly in relation to the realisation in practice of the stated project values human rights, gender equality and social inclusion?

We will start by describing the projects' context, present our approach and methodology, and consider the relevant literature. We will then discuss the role of TA in Nepal brokering behaviour change (in particular with regard to gender equality), as well as examples of the 'no TA' situation. We finish with a discussion on whose values count.

\section{BACKGROUND}

Since 1989, Finland and Nepal have supported bilateral, grant-funded water projects - rural water supply, sanitation, or the broader topic of water resources management for productive use. The two current water projects are implemented in 24 of the 75 districts (now restructured) in western and far west Nepal. They have broad coverage, both geographically and over time. The projects are embedded in local government planning and management systems, but with international and Nepali advisors (contracted by consulting companies) providing technical expertise for planning, capacity and approach development, and monitoring.

Finnish bilateral cooperation began in Nepal in 1989, and in the start, most of the scheme construction was done by the project TA themselves. By 1995, the process had developed, based 
on lessons learned (and changing understanding of development management). Specifically, a district water supply and sanitation fund was established (supporting decentralised management), and funds and management control were channelled through water user committees - at the time, a new concept. In addition, a gender strategy was introduced, extensive capacity building provided at community level, and a Step-By-Step process (SBS) established for water scheme planning and construction guidance. (RWSSSP, 2005)

There are now two on-going projects, built on these antecedents. The Rural Water Supply and Sanitation Project in Western Nepal Phase II (RWSSP-WN) focuses on rural water supply and sanitation. The purpose is 'to ensure the poorest and excluded households' rights to access safe and sustainable domestic water, good health and hygiene through a decentralised governance system’ (project document, www.rwsspwn.org.np). The Rural Village Water Resources Management Project (RVWRMP) in the far west of Nepal carries out rural development via water resources management. Water use here is considered to include a broader scope than just water and sanitation, encompassing agriculture, cooperatives, renewable energy and irrigation. The purpose is 'to achieve universal access to basic WASH services, and improved livelihoods with establishment of functional planning and implementation frameworks for all water users and livelihoods promotion in the project area' (project document, www.rvwrmp.org.np). In other words, both have strongly stated, value based aims to influence the local governance systems via rights-based approaches.

Rural Nepal is a multidimensional environment, characterised by extreme poverty, remoteness, rugged terrain and difficult access, food insecurity, water scarcity, and low human capabilities. Conflict, climate change and a huge diversity of participants (caste, ethnicity, language, religion, etc.) make this a difficult location to live and work. Water is one of the most basic necessities for local people. 
Both projects have a relatively traditional bilateral project set-up, with a team of Nepali and international advisors and staff, working with the Nepalese local government structure. Local facilitators are recruited to support the project implementation at community level. They form the majority of project personnel; while the TA constitute the solid core of skilled specialists, who plan, organise and supervise the project activities. The TA work on technical issues (such as good quality design, supervision and monitoring of the water schemes) and social issues. They develop institutional capacities through training, guiding and insisting on application of project rules and the SBS approach. The SBS is a participatory, interactive planning and implementation process, focused on the User Committees, which includes application of strict financial rules to ensure quality procurement of materials, good governance and transparency. It also gives technical and process advice on the implementation process from scheme planning to postconstruction operation and maintenance. This includes rules on quotas for women's participation at all stages, training plans and materials, etc.

Finnish Development Policy (MFA 2012, 2016) emphasises human rights, anti-corruption, and support for minorities as a framework for development cooperation. Gender equality and enhancing the role of women in development are important cross-cutting issues within Finnish Development Policy. In addition there is an expectation that Nepali guidelines, such as the Water Sector Development Plan, and the National Sanitation and Hygiene Master Plan, are applied at local level in water activities. Gender Equality and Social Inclusion (GESI) policies and processes have been developed by Nepalese government ministries, however they less apparent in action in local government operations.

The two projects have developed a Human Rights Based Approach and Gender Equality and Social Inclusion (HRBA and GESI) Strategy and Action Plan (RWSSPWN, 2015). The aim is to 
identify entry points to trigger adoption of practices that lead to increased and equitable access to opportunities, resources and meaningful participation in decision-making, particularly for women, the poor and socially excluded (extending beyond the project activities). It also supports the implementation of the United Nations Right to Water and Sanitation (UN, 2010), signed by Nepal. These policies, approaches and strategies set the collective value-basis for the project operations in practice.

\section{APPROACH AND METHODOLOGY}

\section{Approach}

This article reflects some of the key research on bricolage and brokerage, and the application of policy by TA in the case settings. We consider the role of development projects in general, and the Finland-Nepal water projects specifically. We put a special focus on human rights, gender equality and social inclusion, and equitable community participation - and the role of technical assistance in translating these principles into practice.

We argue that all the actors in the implementation chain - from donor ministry and embassy, consulting company, international and national TA, community level facilitators and even community - play a dual role. In Figure 1, we have placed TA in the middle role, as this is the focus of our article, but other actors could also be in this position. TA receive facilitation and respond to guidance and orders from above, while providing continuous empirical learning, innovations and feedback to the policy level. At the same time they provide facilitation, guidance and control to those below them, while learning from experience and receiving feedback from below. This is a process of translation or bricolage, whereby theoretical constructs or models are 
made real through practice, and are adapted to suit the local situation (Behrends et al, 2014;

Cleaver, 2012; Mosse, 2005). In our case, technical assistance staff must tread a complex role between respecting the intentions of the donor and recipient governments; and the local cultures and realities of the local setting, while brokering a change.

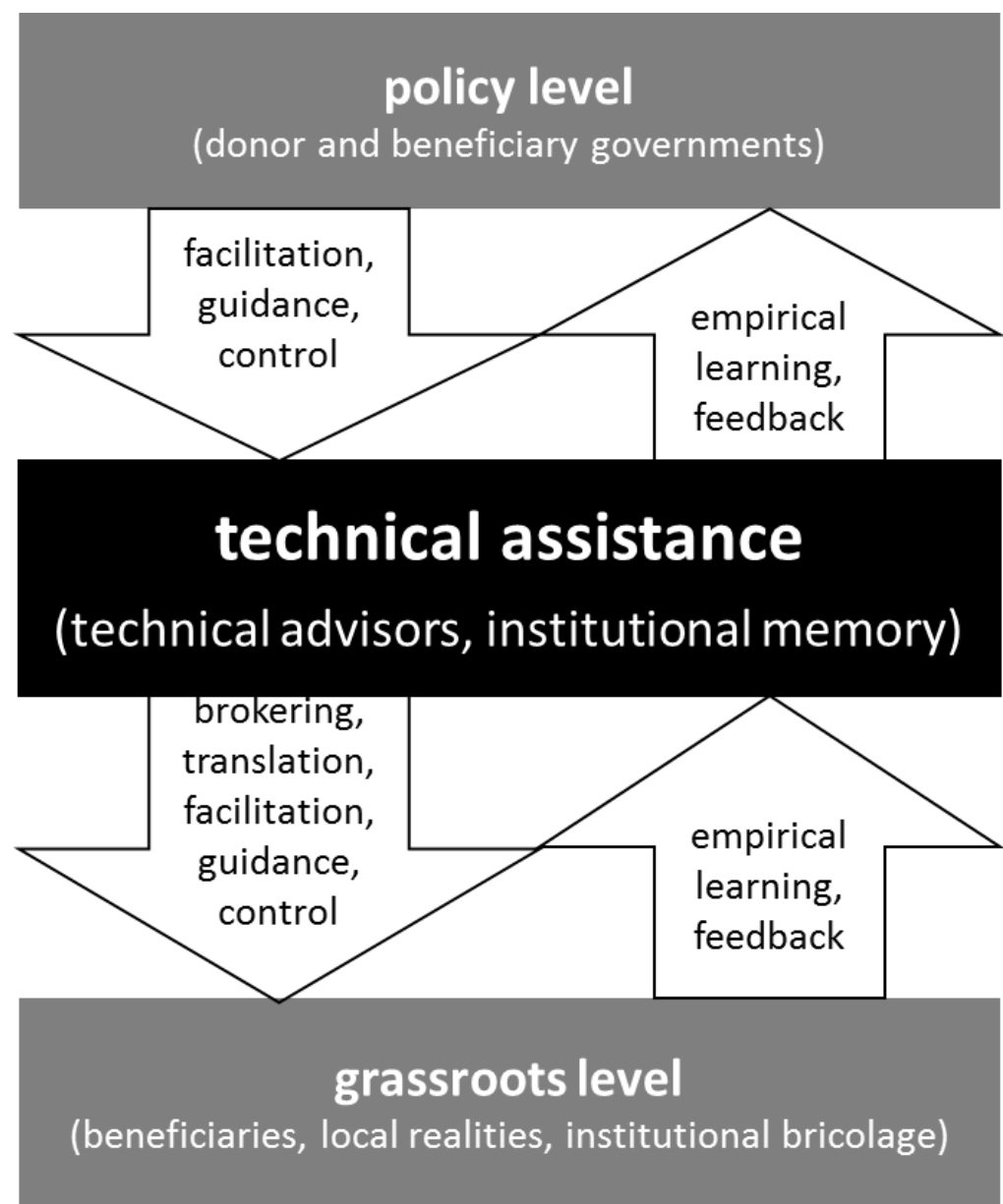

Figure 1. Technical Assistance as Dual Role Actors (developed by the authors)

\section{Methods}

The study relies on research focusing on 'aidnography' (ethnography of aid), translation or bricolage of models to new settings; institutional models; as well as research on gender studies. In addition, we draw on data collected in the case study projects during the long presence in the field by the researchers. 
We use case study methodology, focusing on two examples of the 'with TA' case and discuss the implications, citing examples of the 'without TA case' or 'minimalist intervention TA case'. The dependent variable is the degree to which the policies of the donor are put into practice, while the independent variable is the presence or absence of TA. This is not, however, an impact evaluation.

For specific empirical evidence, the lead author carried out taped semi-structured interviews with TA and donor representatives in Finland, selected based on their long experience with bilateral development projects and policy making. Interviews were conducted with 12 Ministry for Foreign Affairs of Finland (MFA) and embassy staff, and 14 TA (though some had served in both roles). Interviews explored the role of TA vis-à-vis the MFA and local stakeholders, and the institutional elements controlling their work (as well as other aid actors). The interviews were coded to extract key themes. In addition, field interviews were conducted by both authors between 2010 and 2018 with many local government staff and community beneficiaries in Western and Far West Nepal in the project working areas; and international and local project staff. In these interviews we discussed development modalities and TA. We compared project and non-project scenarios, the means of transferring policy to practice, and particularly the role of the advisors. Project reports, memos, blogs and other data complemented the interviews.

One of the authors currently works for a Finnish consulting company, managing both the Nepali water projects, and at times, implementing short term consultancies. Therefore she is an insider. This gives her access to information on development cooperation processes and local actors, but naturally runs the risk of influencing her judgement. The other author was a doctoral researcher at the time of writing. He has carried out field research in both projects for nine months 
altogether, but he is independent of them. Therefore, he brings an external viewpoint to the studied projects, and hopefully limits potential bias.

\section{TECHNICAL ADVISORS IN ACADEMIC LITERATURE}

For many years donors avoided projects and technical assistance altogether, preferring to provide financial support directly, but in the last decade there has been waning enthusiasm of donor governments for budget support, for many reasons (Odén and Wohlgemuth, 2011). There has been a realisation that technical skills are needed if the donor has an interest to see their policies implemented. Naturally, whether this is the best way to do development has been the subject of considerable debate, but we do not deal with that here.

We use the terms 'brokering', 'co-production', 'translating' and 'facilitating bricolage' throughout the article. They convey a similar idea, with some difference of emphasis and power. Some researchers have described the role of TA in translating policy to practice (eg. Mosse, 2005; Olivier de Sardan, 2005; Gibson et al, 2005; Mayer, 2017). These voices understand TA as active, expert actors with varying contextual understandings and critical perspectives to development, and complex personal motivations.

Brokers can be considered to be bridges or intermediaries of knowledge, ideas and practices. This can include top-down or bottom-up simple transfers, or more nuanced development of capacities in a local setting and relationship building. Mosse (2005) notes that as brokers of development policy, TA must be concerned as much with building and maintaining coherent meanings and representations as with the more traditional functional roles that might be supposed by their Terms of Reference. He also described the role of TA mediating at the 
interface between project operations and donor policy, interpreting each to the other. We consider that the TA of our case study projects clearly take this role.

Wilson (2007) discussed the changing role of technical cooperation over the years, moving from the idea of top-down knowledge transfer, to capacity building and finally innovation and coproduction. He argued that now advisors serve 'not only as a resource for learning 'from' other stakeholders, but also for creating new knowledge 'with' them'. (p. 196). This can be clearly seen in the change in water cooperation in Nepal and elsewhere, from the early days of construction by the team, to community-based management now.

Behrends et al (2014) consider how ideas, knowledge or techniques come to a new setting. 'Translating models means that they travel by being conveyed, carried, picked up, called for and interpreted by various actors or - as we will call them - mediators.' (p.2) However the model cannot be assumed to operate in the same way within a different social setting and 'rationality'. Hence it cannot be assumed, as we discuss later in this article, that a development model from another country can be transplanted smoothly. Tandon (2010) described how capacity development, if it genuinely aims to reach the marginalised, 'involves the bumping together and shifting of power relations and practices that have hitherto been accepted as "the way things are"'.' (p.94). He stresses that it is impossible for practitioners to avoid taking some sort of stand, when planning and implementing activities. We argue in this article that this is the role of the TA in the two projects.

Cleaver (2012) also considers the way models or institutional arrangements are reshaped via bricolage, involving a do-it-yourself institutional development by the local community, water committee or other organisation (though not without risk). This can be deliberately facilitated by TA, or can happen unintentionally. Haapala et al (2016) looked at the way this happened in 
practice in one of the case study projects. This can be challenging, as there is a risk of elite capture, and may mean the project processes are subverted; but there is also a chance to develop new innovations.

Scott (2008) reviewed approaches to institutional development over the last three decades. $\mathrm{He}$ described the elements underlying institutional order as regulative, normative and culturalcognitive. These categories can also be considered to constrain and also to facilitate the good fit of the projects, depending on the skills of the TA and the interest and activity of the community. We describe here how TA of Finnish bilateral projects work within all of these elements (Figure 2, developed by the authors).

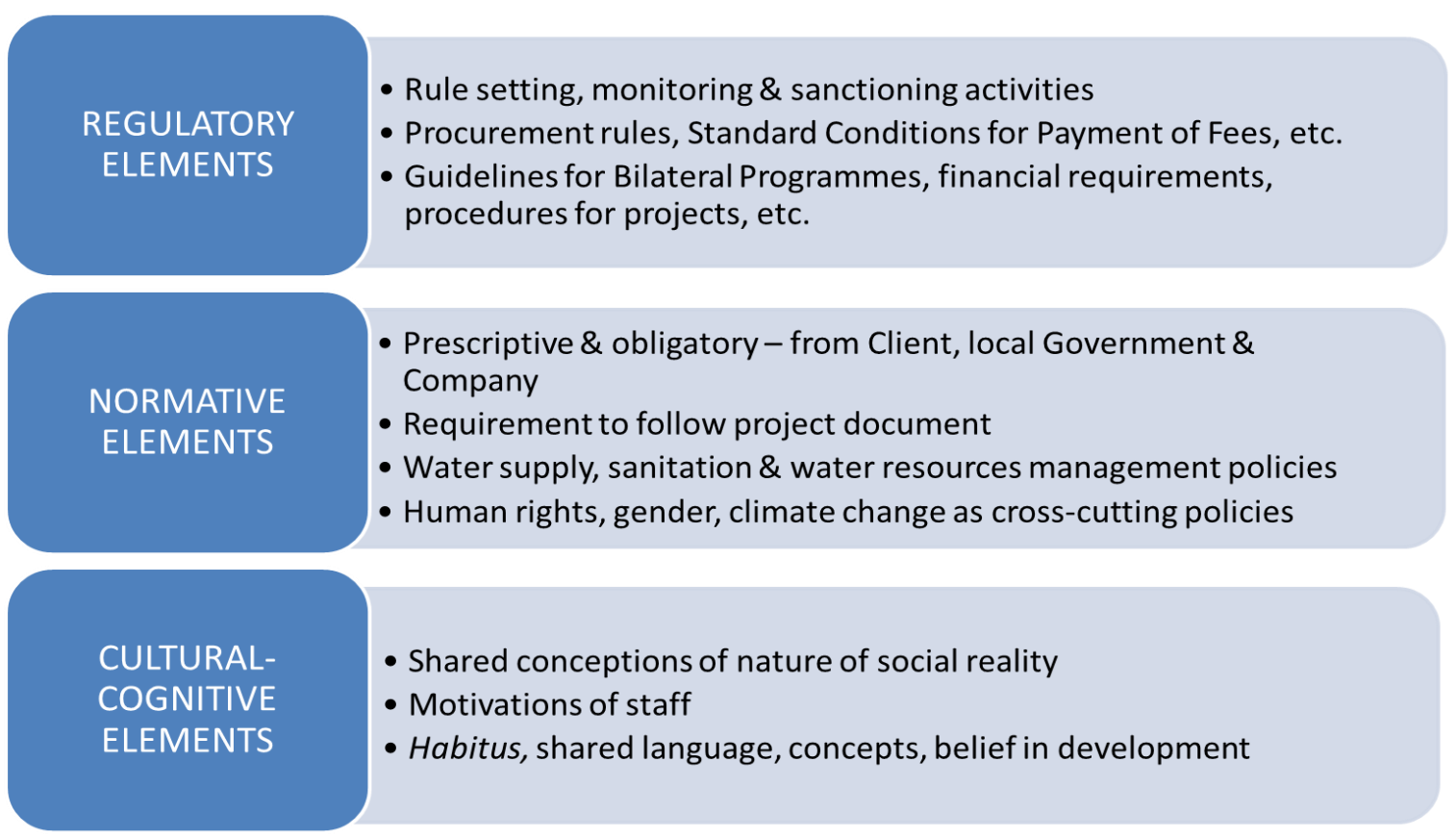

Figure 2. Institutional Elements Governing Bilateral Cooperation and Technical Advisors

Regulatory elements could be considered to be the financial and administrative rules and guidance set by the donor and the recipient government in contracts, and followed up with evaluation and auditing. One reason for the above-mentioned move by donors away from budget support is an interest to ensure finances are better controlled, and typically TA are used to do 
this. In our case study projects the advisors must play a strong controlling role, fortifying financial good governance. However, there are also risks that micro-management and excessive risk-avoidance imposed from above on each project level (for instance, donor to TA; and TA to user committees) can stifle innovations and lead to delays. The development of the SBS process contributes by providing clear steps for procurement and auditing. Haapala et al (2016) demonstrates how the projects use bricolage to find a good fit of these steps with community preference. However, a balance is needed between good governance and appropriate practice.

Normative elements bring a prescriptive and obligatory side to development, including the behavioural expectations of the advisors - 'what they ought to do'. They provide the tools of the trade such as logical frameworks, theories of change, report formats, and an expectation (explicit or implicit) by the donor of how the TA should behave (Stirrat, 2000). Mayer (2017) discusses the challenges of implementing the normative concepts of development policies and cooperation, and the contradictions in practice - 'in development politics and development cooperation, the conflicts and collisions are often more glaring and blatant than in other fields, since the official goals are often so graceful and altruistic.' (p.53)

The MFA provides various guidelines, which TA are expected to use in implementing projects for instance, the development policy and guidelines covering topics such as HRBA. The Government of Nepal has their own policies and strategies for use in field activities. TA are compelled to observe the regulations and norms of the donor agencies, which in turn need to respond to the demands of their taxpayers or contributing governments for simple narratives and clear results for their money. One respondent, earlier working for the MFA, commented 'there is quite a lot of time and energy spent on policies and country strategies. It is quite an important part of the work, but I think it is kind of high level. You can read them and they are so generic so 
they fit anything. It communicates Finnish values. But they can be implemented in so many ways.' (C7)

Project documents have been agreed to by the donor and recipient governments. However, the advisors can make the difference of whether or not local level recipients are in reality consulted and included in the implementation process. This depends on their ability for bricolage, to adapt guidelines to local conditions and field work (Cleaver, 2012, Haapala et al., 2016). TA need creative ability for everyday problem solving in the communities, as well as for continuous development of the intervention. Innovations gradually are included into institutional memory. The significance of the technical assistance comes from this role of understanding local realities and working with them, along with brokering policy into praxis.

Cultural-cognitive elements are the shared conceptions that constitute the nature of social reality and the frames though which meaning is made - the motivations, the shared language, beliefs and concepts of development, or habitus. Stirrat (2000) described consultants as cultural performers, whose reports were an exemplification of the values of modernism. Earlier research by White (2015) has indicated a development cooperation habitus among Finns working in development, giving a shared vocabulary and ethical viewpoint. A worker may practice selfcensorship because he/she wishes to continue working in development and not to alienate potential donors or co-workers (Mosse 2011, Hänninen 2014). In the case of the Nepal water projects many staff (local and international) have worked together for years, building the habitus as well as institutional memory. One of the project respondents commented on the importance of these values 'Transparency, accountability, rule of law. Things that aren't always obviously outlined in the project document but are important. What we are maintaining internally in our management and in our external dealings.' (C8) 


\section{THE ROLE OF TECHNICAL ADVISORS IN AID INTERVENTIONS}

\section{Technical advisors in Nepal}

Finnish TA working in water and sanitation projects have changed over the years. The early emphasis was on large teams with hard engineering skills. Now there are small teams with an increased focus on social skills (Koponen et al 2012). In addition, advisors used to be almost entirely men. Many women now participate.

Olivier de Sardan (2005) describes two paradigms that provide an overall justification (though at times conflicting) of the professional practices of practitioners, regardless of their ideological, moral or political orientations: 'a) Development seeks the welfare of others (the altruist paradigm). Hence its strong moral connotation. b) Development implies technical and economic progress (the modernist paradigm). Hence its strong evolutionist and technicist connotation.'

(p.13) He also notes the critical role the development practitioner plays, translating the technical aspects to the local social milieu and finding a balance between the two paradigms. Yet TA have rarely been trained in these aspects - beyond their initial professional training they must learn on the job.

International advisors must take care in positioning themselves - they are in a position of power to approve activities and withhold money. There is always a risk that they will fall into a role of benevolent leader or white saviour, but they are simultaneously in a somewhat marginalised position. In the case study projects, international advisors are usually only basic Nepali speakers, outside of the caste hierarchy and local knowledge systems, and are often women themselves although in this setting they are often treated as honorary men (personal experience of the authors and reflected in interviews with female advisors). As of early 2018, Chief Technical Advisors of both projects were female Finnish water engineers, while RVWRMP also had a male 
Dutch agricultural advisor. All have more than 20 years' of development experience in a range of roles and countries. There were also a male and a female Finnish junior advisors, both of whom have backgrounds in engineering and social issues.

Nepali technical staff in the projects tend to come from either engineering or rural development backgrounds. During the staff selection process positive discrimination is applied, in an attempt to recruit women, ethnic minorities, disadvantaged castes and minority religions. However, this has been relatively unsuccessful (recruitment guidelines of both projects, recruitment memos and personal experience). Women face considerable difficulties to study and work in this maledominated field and to be recognised as equal. A recent blog on the RVWRMP website quoted one of the rare young female engineers, Aayisha Khati 'it is not always easy to work in such a male dominated environment. I have noticed that on field monitoring visits my colleagues do not expect as much from me because I am a woman.' ${ }^{1}$. It is also difficult to identify qualified women with sufficient experience and the willingness to travel in the field for long periods, especially in Far West Nepal.

As a result, the local advisor posts are dominated by men from advantaged castes. Udas and Zwarteveen (2010) argue that the professional culture and incentives of predominantly male, higher caste engineers in the Nepalese Department of Irrigation inhibit gender mainstreaming in that sector (closely linked to the water and sanitation sector). Hence the question arises whether local or international advisors are more or less able to deal with local cultural issues remembering that in many cases 'local' advisors may come from a different class, caste, ethnic group and geographic area. It appears that individual qualities such as the ability to work with an open and generous outlook, and focus on the marginal beneficiaries, are important. 
We will continue here by considering some of the complexities faced by TA in brokering policies, and their value-basis, into practice.

\section{Brokering gender equality and the right to water}

Women in rural Nepal experience discriminatory practices which prevent them from fully exercising their rights and capabilities. These practices, which are based on fear, fate, beliefs and power, keep women and disadvantaged groups in a subordinate position. As a result they lack equal access to educational, social and economic opportunities. Aasland and Haug (2008) describe how caste, ethnicity (and religion) and gender are factors that determine access to assets, capabilities and voice, based on socially defined identity. Regmi and Fawcett (1999) argued that unless Nepali water projects identify fundamental causes of women's subordination and then attempt to empower women, sustainable changes would not be made.

Therefore the projects have taken the line that affirmative action is needed, not only to compensate for past oppression and discrimination, but also to mitigate the influence of current biases and blindness of institutions and decision-makers. Without active steps being taken, there is a risk that activities of the projects could worsen the dominance of local elites (Rusca and Schwartz 2014).

Implementation of the ideas of gender equality, social inclusion and human rights at grassroots level is a challenging process. At the policy level the recent Nepali Water Supply, Sanitation and Hygiene Sector Development Plan (GoN 2016) includes many references to the right to water and sanitation. Nepal signed the UN Right to Water and Sanitation in 2010 (UN, 2010). Meier et al (2014) found that while there is political will at the top to engage with human rights law conceptually, there is limited guidance on how to apply human rights in water provision locally. 
Partly this is a question of limited budget, and particularly weak local administration, especially in remote locations like the Far West. It is not enough simply to mandate the right to water and sanitation. TA must give guidance, both to inform local actors and to support them to work out how it can function concretely.

An MFA respondent commented 'I'm pragmatic - I'm not dreaming that doing something on human rights will change everything. There are no simple solutions. You have to really work from the ground with the people and organisations to make a difference... we need that sort of thinking because the development policy is sometimes escaping from the reality' (M4)

This is where the role of technical assistance comes in. The project staff in Nepal work with local duty bearers (such as the newly elected rural municipalities), providing training on what the right to water means in practice, and turning normative guidance (as in Figure 2) into practical results in the field. They have fed lessons from the field upwards to the development of the water and sanitation Sector Development Plan (as illustrated in Figure 1) and internationally, including via contributions to the UN Special Rapporteur on the human right to safe drinking water and sanitation (de Albuquerque, 2013). Merry (2006) studied the translation of human rights law to local cultures, and vice versa. She noted the importance of activists who serve as intermediaries between different cultural understandings, as in our case study.

The HRBA and GESI Strategy and Action Plan of both projects (RWSSP-WN 2015) guides mainstreaming of HRBA and GESI principles into all stages of the project and local government planning cycle. In addition, targeted actions are included where additional focus of efforts and resources is needed (eg. menstruation issues, disability), and it outlines necessary capacity building for the local duty bearers. However, as noted earlier, it is difficult to expect that normative guidelines - even those prepared locally - would lead to achievement of rights without 
TA and facilitators working at community level to introduce them, raise awareness and interest, and where needed, to enforce them.

Since women and girls are the hardest hit by hours of carrying water, specific steps are taken to ensure their involvement in decision-making. Involvement in water resource management projects gives an opportunity for women participants to build their self-confidence and selfesteem and provide opportunities for them to pursue their livelihoods. Representation and participation in water user management groups, including micro-irrigation and hydropower schemes, as well as a range of livelihoods trainings, provide a forum that enables them to voice their interests and needs.

Typically projects set quotas for participation in user committees - in this case, 50 per cent women, and proportional representation of ethnic and caste groups. However, it can be difficult to find people from these groups who are literate and confident enough for committee roles. Leder et al (2017) noted that complexities of social relations, including the intersection of caste and gender, can interfere with the best intentions of equality and mainstreaming. However, the projects they studied appeared to leave decisions on who benefited to existing local power brokers. This is seen Nepal-wide. The two Finnish projects demonstrate greater involvement of women than the national norm, perhaps influenced by hands-on support and the challenging of the status quo (White et al 2015).

Representation on paper does not guarantee effective governance. Arora-Jonsson (2012, in her research on community forest management in India and Sweden) describes how women 'were 'mobilised' to work for the activities of the associations and committees. But it did not mean that they were automatically part of the decision-making' (p. 159). In fact, they resented the feeling that they were being forced against their will to come to meetings just to listen to the men speak. 
In India, her respondents commented that it was easier to express their views in meetings if their male relatives were not present, and were not inhibited by the traditional gender and power relations. In the case projects, separate meetings for women only are held in every water supply scheme to decide the location of taps, aiming to avoid a situation where men's interests are monopolising the discussion and decision-making regarding a resource that is mainly the domain of women.

The TA of both Nepal projects have introduced confidence-building workshops within the planning process for women in an effort to build their confidence and to encourage them to actively speak up in larger meetings. Leadership training is provided to women from User Committees. Since December 2017, RVWRMP has implemented 'Women as Decision-Makers' events with women elected to Rural Municipalities (and female civil servants), to support them to identify gender-responsive activities and budgets. (RVWRMP event reports, 2017 and 2018). There are still constraints, such as the women needing to leave early to attend to their household duties; or lacking sufficient literacy skills. However, confidence and active participation of women is increasing. Women are enthusiastic to attend meetings despite the time burden. 'It takes time for us but it is worth it' (RVWRMP, Field report, 2013).

In interviews, project staff explained the importance of striking a balance between carrying out awareness-raising, and working with community to actually construct infrastructure. The risk of a programmatic approach is that it is too theoretical, with nothing happening on the ground. Doty (2016) carried out research in RVWRMP. Particularly, she noted the behaviours of the project actors themselves were important - emphasising transparency, local knowledge and contacts, participatory processes, gender and social inclusion and local ownership. 
The long-term TA can play an important role by providing skilful facilitation, constantly raising the topic of gender, supporting women to speak in meetings, promoting them for leadership roles, and ensuring that social inclusion is taken from theory to practice (as noted by Tandon, 2010). This is brokerage or translation in action: theoretical policy concepts of gender equality and social inclusion are developed by advisors into practical ideas that are tested at local level. Local bricolage is facilitated, and the improved concepts are reported back to national and international stakeholders (as in Figure 1). Bricolage does carry risks that the process can be derailed by dominant elites, hence it needs close monitoring. (Haapala et al, 2016)

There is always a risk as implementation depends on individuals. If an instrumentalist approach dominates - focusing on the construction of infrastructure only, rather than capacity development and rights - it would be simpler to work within the existing system, and not challenge it. An 'arrogant' advisor (local or international), or one who identifies more with the elites, may have a negative impact. There are also examples of advisors applying foreign ideas that are not suitable to the local environment. This is where the cultural/cognitive element and habitus of the project staff is important - constantly reinforcing the importance of the margins.

\section{Understanding local realities and social dynamics}

People who are working in the local environment, be they international or local advisors, gain an understanding of the local dynamics. Admittedly, the understanding is imperfect, but probably better than national level government or donor staff, due to their continuing contacts and presence. Together with local government they apply the 'rules of the game', by guiding communities through the projects' SBS process and arguing for human rights principles- such as participation, equality, non-discrimination, inclusion, transparency and accountability. 
None of us lives our whole life in a state of subordination. Even those identified as 'disadvantaged' have different power relations in different environments. A Dalit man may be subordinate to a Brahman woman, yet when she is menstruating she becomes untouchable to all. Binary categories of men/women, old/young, 'high' caste/'low' caste should not be assumed. All women are not a cohesive group, just as all men are not, and this is something that the TA have tried to emphasise. Leder et al (2017) studied four water projects in far west Nepal (not the Finnish projects) and found that 'differences between women - such as age, marital status, caste, remittance flow, and land ownership - led to some women benefiting more than others. Water programmes must recognise and address difference between women if the poorest and most disadvantaged women are to benefit.' (p. 235)

A difficult issue in the working areas of RVWRMP is the discriminatory behaviour linked to menstruation. For religious and cultural reasons, women are considered untouchable and are prevented from using the toilet and tap. In many communities they are forced to sleep in outside sheds ('chhaupadi huts') during menstruation (Haapala and White, 2015). This directly runs against the UN Right to Water and Sanitation (including access to sanitation that is safe, hygienic, secure, socially and culturally acceptable, provides privacy and ensures dignity) and many other human rights, and leads to deaths in the project area each year ${ }^{2}$. It is also a technical problem - non-use of toilets during menstruation leads to poor sanitation outcomes for everyone. This is a value issue that the project is taking a strong position on - backed up by (and feeding back to) national government directives, and now draft legislation ${ }^{3}$. However, it has proved very resistant to change.

How can staff change local cultural norms? Simply applying sanctions doesn't work. During one community meeting, when barriers to menstruating women were discussed, a local priest arrived. He immediately became angry and started shouting to the women - 'Why are you telling them 
you don't use the toilet - you should be saying that you do use it!' (RVWRMP field report, 2016). This is important because at present, after some prompting and developing relationships, the community members are still willing to openly discuss menstruation-linked barriers. However, if a sanction is applied by the national government, they will quickly begin to hide what they are doing. Instead, the continuing slow process of behaviour change communication is needed, 'translating' the policy to local conditions, identifying tailored messages and activities for different groups, and holding regular interactions with key religious leaders and elderly men and women. Project facilitators living in villages know who are not using toilets, and nudge a change in values and practice with the 'carrot' of infrastructure improvements.

Behaviour change campaigning hasn't been all positive. In rare cases, TA-supported campaigns to destroy chhaupadi huts made the situation of women even worse, as they are forced to sleep in the open air (Haapala and White, 2015). Simply applying a national policy (or the norms of the Finnish Government) is likely to be ineffective or even counter-productive.

Projects need to balance the concerns of democratic decision making - where the majority rules - with the need to include minorities. Should priorities set by donors take precedence over local priorities? Clearly some stakeholders consider it should be outside the scope of a foreign-funded project. The reality is that the projects have been dealing with un-elected (until the very recent local elections in Nepal in 2017) government representatives who are usually from an advantaged caste, majority ethnicity and male. Even at local level, village leaders are not usually from minority groups. It is the same for TA and bureaucrats, whether foreign or local. They are neither elected nor local, and yet wield a great deal of authority over the decisions taken.

Typically projects require participatory approaches, but since communities are not a homogenous group, whose view counts? If GESI and human rights are not dealt with, it is likely 
that problems with sustainability of water schemes will arise in the long term, and conflict could return to the region. One option is to step back and hope that the community will organise and make change themselves. Another option is that projects facilitate change via the active presence of TA at grassroots level. It is often the small everyday decision making, influenced by TA values that can have an important effect on the projects. One respondent noted 'being an outsider is helpful sometimes. If you are inside the system there is always the hierarchy and someone else can decide what is the right thing to say'. (C11) Advisors' understanding of the local context, the possible ways to apply the top-down orders to local cultural strata, becomes important. As in Figure 1, they translate the policies and values from above into practice, and the lessons learned and bricolage solutions reached can be fed upwards to policy makers.

\section{Does technical assistance make a difference?}

Given that projects of this kind involve both advisors and money, it is valuable to compare our cases with the situation where technical assistance was minimised, but money was provided. Initial research indicates there is a difference, though we emphasise that this paper is not an impact evaluation. The first phase of RWSSP-WN had an approach that can serve as a useful comparison. The advisors of Phase I aimed for a more sectoral approach (as applied in another Finnish partner country), stepping away from the experiences of the earlier Finnish projects in Nepal. This approach was not translated specifically to the local setting. TA did not carry out implementation and monitoring of project activities at local level. Instead they provided funding and left the districts to follow normal government practices. The Mid-Term Review was critical of this hands-off approach (Vikman, 2011). The local facilitators didn't stay in the communities but lived in district headquarters. Their presence in the community was limited - if something went wrong it could take time for the community to get assistance. It was also difficult to 
monitor what was happening without regular access. No firm targets for women's participation were set other than what were available in the sector, and instead the project guidelines used vague requests for inclusion. The participation of women and disadvantaged groups in project committees and activities was less than anticipated (in comparison, for instance, with the earlier phases of the Finnish projects, or with RVWRMP). These problems were expressed later in interviews with local project facilitators who had worked in both phases, and also by a study, which found inconsistencies in the GESI guidelines and practice in the first phase (Welber, 2012). Facilitators complained that in Phase I there was very limited community ownership and understanding of local responsibilities (N2). For Phase II the two governments decided to move back to a more hands-on approach.

What is the totally 'without-TA experience'? The Government of Nepal has its own process for rural community-level water scheme construction. During field interviews in 2016 (N1), a Local Development Officer and District Engineer discussed the Government's 14-stage planning process, however, they said it is not often followed in practice. In particular, they said the disadvantage of the district planning process is the lack of facilitators, who in the project case can support the community to develop proposals and prioritise schemes equitably. Without them, they indicated it is the noisiest, more advantaged groups whose schemes are selected. These government staff stated that with RWSSP-WN's SBS approach, the community takes ownership and contribute more cash and labour. The result (in their opinion) is that the project is finished on time and is much more sustainable. Facilitators get meaningful participation in committees, including a higher percentage of active women (N1).

In 2016 we asked the opinion of the field staff of RVWRMP in two project districts about different modalities. The answers were obviously partial, but our observations in the field strongly support their views, as do interviews held with local government staff and communities. 
In both districts, the staff noted that in RVWRMP schemes there was regular monitoring due to the continuous presence of the staff; better transparency; more meaningful participation by all stakeholders and interest groups; and better inclusion of the poor and disabled than in the nonproject schemes. Furthermore, they considered that project guidelines steer the work for good and protect the local institutions from corrupt practices, such as falsified selection process for water user committee members or corrupt procurement.

Our observations in the field (2010-2018) match with this view, stressing the significance of technical facilitation in the implementation at the grassroots level as the only way to ensure theoretical policies are applied. Naturally this implies higher personnel costs (though the staff and transaction cost for government schemes are impossible to calculate). However, it also achieves more sustainable results, in the form of greater functionality of schemes compared with the national average (White et al 2015). This conclusion seems obvious to local government and project staff, yet it remains still largely ignored in the literature and within donor governments.

\section{Whose values count?}

This leads to interesting reflections on the competing positions of ownership, democratic decision making and power. Project modalities have often been criticised for not creating real change, but instead just providing inputs of technical advice or goods for a limited period in a limited area. In this case study, the TA are also playing a role of social mobilisation, aiming for fundamental change in the community. Project staff are encouraged (in project guidelines, training, meetings and hand-on support) to consider the experiences and views of disenfranchised community members, and thus be better able to support those at the margins of power to know and claim their rights to basic water and sanitation. Both mainstreaming and 
targeted actions are used to promote equality. This is monitored and discussed in the staff performance reviews.

Koponen et al (2012) noted that in Finnish water sector cooperation in Nepal 'the Finnish valueadded appeared more as a set of values' - specifically transparency and accountability (p.70). They commended 'Finnish TA's attempts at mainstreaming gender in the step-by-step approach in the various water supply and sanitation projects, as well as in the fact that the projects have supported water supply and sanitation in areas that have low human development index (HDI) or are operating in regions that are far from the capital and hence have low infrastructure development. This latter can be seen as a Finnish value of supporting social equality and supporting vulnerable groups.' (p.71)

As noted earlier, there are many potential viewpoints and values operating in a project setting. It could be argued that the projects and staff are acting in a neo-colonialist fashion, imposing Nordic ideals of gender relations and social inclusion on a totally different society. Policies and projects are not value neutral. This is the risk of all development aid interventions. The alternative option might be to do nothing and allow the status quo to continue. This would not be a neutral attitude either. All actions and decisions have a value basis of some sort, including inaction. Inaction would support social exclusion, unequal access to water resources, and dominance by local elites (Rusca and Schwartz 2014). The question is how reasonable and justified are the values the powerful stakeholders employ, and which values best support the achievement of set targets at the grassroots level.

In this case, the project applies the best practices of the sector (such as community management and social inclusion) and mutual norms and agreements between the main stakeholders (such as promotion of human rights) (Figure 2). These are not purely the attitudes of the donor and their 
TA. The actions of the project are in line with Nepalese government policy (though some, such as Hänninen, 2014, have argued that the policies and strategies themselves have been written to reflect donor priorities, and are not a genuine reflection of local values). It is the traditional practices of the local government staff and community (elites) that are sometimes out of step with national policies and bilateral agreements. In the communities, benefitting women and disadvantaged groups are willing to back the value-basis of the intervention that promotes gender equality and social inclusion, though acceptance isn't uniform. There is local support expressed for the interventions' ways of working in the field. By facilitating any sort of questioning of traditional norms in the community, change is provoked.

One more argument for development interventions and technical assistance is that many of the developments in the rural water sector aim to enhance the most basic human rights, such as basic nourishment and health, a target shared by all human beings. They are not dependent on cultural conditions or values. There is no culture that would prefer more diarrhoea or a dirty environment. Some outsiders might consider the idea of letting women and girls collect water from a spring in traditional manner to be culturally appropriate. However, the women themselves universally express their satisfaction to be relieved of the hard grind of carrying dirty water on steep hillsides for hours each day. Development of these basic conditions could be more easily seen as meeting the shared view of all humanity of the basis for a good life, rather than as cultural value exports.

We argue there is evidence that the value basis of the intervention can build the capacities of the communities to meet their needs, as well as the project targets. A still problematic issue is how to ensure that HRBA and GESI changes are institutionalised and sustainable in the future, without project staff to support them. Since local government staff don't have the time or funding to continue the same level of facilitation, we need to ensure the behaviour changes are embedded in 
the community before the project ends. Long term technical assistance has been crucial for ensuring this in the Nepali cases.

\section{CONCLUSION}

We asked what role the technical advisors play in project implementation in the case study projects, particularly in relation to the realisation in practice of the stated project values - human rights, gender equality and social inclusion?

The environment of rural Nepal (and particularly in the remote Far West) is complex and lacks strong and effective local governance (though the future is promising with recent elections and installation of local municipalities). We argue that advisors act as important brokers in the centre of the implementation chain, linking policy, resources and rules from above, with field experiences, problem-solving and institutional-memory (as in Figure 1, and Mosse 2005) - a two-way flow of learning. This relies on not only the normative guidelines from above and the project itself, but also cultural-cognitive elements - the shared habitus of the TA.

TA can apply context-specific understanding of the potential for inclusion and empowerment to ensure that disadvantaged groups are considered (ie. translating ideas). This can facilitate longterm institutional and behavioural changes in the communities towards more equitable and equal participation, taking human rights from a theoretical concept at policy level, into practice.

This carries risks - enforcement of 'rights' could provoke a backlash from the elites at village level, with accusations of donor policies over-riding 'traditional' culture. Consequently the individual qualities of the advisors are important. Thoughtful technical assistance that understands local contexts and aims at long-term changes in local mind-sets has an indispensable 
influence on the outcomes. The project (and its Nepalese and Finnish backers) is walking a line between ensuring universal human rights and imposing external values, by taking the decision that disadvantaged groups count. We argue that all actions and decisions are value laden, so no value-neutral attitude exists. Therefore, the question is how reasonable and justified are the values the powerful stakeholders employ, and which values best support achievement of local needs and the set targets at the grassroots level.

We consider that long term technical assistance enables institutional learning and memory that evolves over time. Such changes could not be carried out without multi-skilled and resourced TA developing the process. Quality technical assistance is central to the maintenance of transparency, good governance and a value basis throughout the intervention process, facilitating inclusion and participation of all.

\section{ENDNOTES}

${ }^{1}$ https://www.rvwrmp.org.np/single-post/2017/09/01/Choosing-to-Thrive-in-a-Male-DominatedProfession

2 https://www.rvwrmp.org.np/single-post/2017/07/25/Menstruating-is-dangerous-business-forwomen-in-Far--and-Mid-Western-Nepal

${ }^{3}$ As of August 2018, the National Penal Code of Nepal will contain Clause 168 (3) which states the act of discrimination by keeping menstruating female or women who has delivered baby on a Chhaupadi or other inhuman behaviour such as not touching, or other inhuman behaviour, to be criminal offenses and Clause 168(4) states the penalty will be imprisonment of up to three months or three thousand rupees or both.

\section{ACKNOWLEDGEMENTS}

We are grateful for the participation of the key informants and project staffs, and the received travel grant from 'Maa- ja vesitekniikan tuki ry.' 


\section{REFERENCES}

Aasland, A. and M. Haug (2008) ‘Social Exclusion in Nepal - stronger or weaker?' Norwegian Institute for Urban and Regional Research, Working Paper 2008:115

Arora-Jonsson, S. (2012) Gender, Development and Environmental Governance: Theorizing Connections. London/New York: Routledge.

Behrends, A., S-J. Park and R. Rottenburg (2014) 'Travelling Models: Introducing an Analytical Concept to Globalisation Studies' in Travelling Models in African Conflict Management. Brill Online.

Cleaver, F. (2012) Development Through Bricolage: Rethinking Institutions for Natural Resources Management. London and New York: Routledge.

de Albuquerque, C. and V. Roaf (2013). On the right track: Good practices in realising the rights to water and sanitation. United Nations Special Rapporteur on the human right to safe drinking water and sanitation, Lisbon, Textype.

Gibson, C., K. Andersson, E. Ostrom and S. Shivakumar (2005) The Samaritan's Dilemma: The Political Economy of Development Aid. Oxford: Oxford University Press. 
Government of Nepal (2016) Nepal Water Supply, Sanitation and Hygiene Sector Development Plan (2016 - 2030). Ministry of Water Supply and Sanitation Sector Efficiency Improvement Unit (SEIU)

Haapala, J. and P. White (2015) 'Why do some behaviours change more easily than others? Water use behaviour interventions in rural Nepal', Waterlines, 34(4)

Haapala, J., Rautanen, S.L., White, P., Keskinen, M. and Varis, O. (2016) 'Facilitating bricolage through more organic institutional designs? The case of water users' associations in rural Nepal'. International Journal of the Commons, 10(2).

Hänninen, E. (2014) Legitimating Aid: Donors and Policy Making in the Rural Water Supply and Sanitation Sector in Nepal. Doctoral Thesis. Publication of the Department of Political and Economic Studies 14 (2014), University of Helsinki. 289 pp.

Koponen, J., M. Suoheimo, S. Rugumamu, S. Sharma and J. Kanner (2012) Finnish ValueAdded: Boon or bane to aid effectiveness? Ministry for Foreign Affairs of Finland, Erweko Oy, Helsinki, 170 pp.

Leder, S., F. Clement and E. Karki (2017) ‘Reframing women's empowerment in water security programmes in Western Nepal.' Gender and Development, Vol. 25, No. 2, 235-251

Mayer, M. (2017) "They Come from Above” Exploring Finnish Development Cooperation in the Field Of Meteorology, 1968-2015. Doctoral Thesis. University of Helsinki. 
Meier, B., G. Kayser, J. Kestenbaum, U. Amjad, F. Dalcanale, and J. Bartram (2014)

'Translating the Human Right to Water and Sanitation into Public Policy Reform', Science and Engineering Ethics, 20 (January 2014), pp. 833-848.

Merry, S.E. (2006) Human Rights and Gender Violence - Translating International Law Into Local Justice. The University of Chicago Press, Chicago and London. 264 pp.

Ministry for Foreign Affairs of Finland (2012) 'Finland's Development Policy Programme Government Decision-in-Principle', 16 February 2012.

Ministry for Foreign Affairs of Finland (2016) Finland's Development Policy: One World, Common Future - Toward sustainable development, Government's Report to Parliament, 4 Feb 2016, Government Publications, Helsinki

Mosse, D. (2005) Cultivating Development: An Ethnography of Aid Policy and Practice. London: Pluto Press.

Mosse, D. (2011) 'Introduction: The anthropology of expertise and professionals in international development', in David Mosse, ed., Adventures in Aidland: The Anthropology of Professionals in International Development, Oxford and New York: Berghahn Books, pp. 1-31.

Odén, B. and L. Wohlgemuth (2011) 'Where is the Paris Agenda heading? Changing relations in Tanzania, Zambia and Mozambique'. ECPDM Briefing Note No. 21, February 2011.

Olivier de Sardan, J-P. (2005) Anthropology and Development. Understanding Contemporary Social Change, Zed Books, ISBN: 9781842774175, 256 pages 
Regmi, S. and B. Fawcett (1999) Integrating gender needs into drinking-water projects in Nepal. Gender and Development 7(3), November 1999:62-72

Rural Water Supply and Sanitation Project - Western Nepal HRBA and GESI Strategy and Action Plan. Human Rights-Based Approach and Gender Equality and Social Inclusion in the Water and Sanitation Sector. RWSSP-WN / DoLIDAR, Nepal (2015). Available from http://www.rwsspwn.org.np/\#!phase-ii-publications/ck0f

Rural Water Supply and Sanitation Support Programme, Nepal, Phase III (RWSSSP III), (2005). Completion Report. Kathmandu. December 2005.

Rusca, M. and K. Schwartz. 2014. 'Going with the Grain': Accommodating Local Institutions in Water Governance. Current Opinion in Environmental Sustainability 11:34-38

Scott, W. R. (2008) 'Approaching adulthood: the maturing of institutional theory'. Theory and Society, (2008) 37:427-442

Stirrat, R. L. (2000) 'Cultures of consultancy', Critique of Anthropology, 20(1):31-46.

Tandon, R. (2010) 'Whose Values Count? Voice, Values and Exclusion in CapacityDevelopment Processes: Experiences from India' in J. Ubels, N. Acquaye-Baddoo and A. Fowler (eds) Capacity Development in Practice. Earthscan, Washington. 338 pp.

Udas, P. and M. Zwarteveen (2010). 'Can water professionals meet gender goals? A case study of the Department of Irrigation in Nepal', Gender and Development, 18(1), March 2010:87-97 
United Nations General Assembly, A/64/292. The human right to water and sanitation. 28 July 2010

Vikman, H. (2011) Mid-term Review of the Strengthening of the Rural Water Supply and Sanitation Project in Western Nepal (RWSSP-WN), MFA Finland.

Welber, E. (2012) Contextualizing Gender Equality and Social Inclusion in the WASH Sector. Locating RWSSP-WN's local level goals in larger frameworks, RWSSP-WN website

White, P. (2015) 'The Spectrum of Motivations, Expectations and Attitudes in Technical Development Cooperation'. Forum for Development Studies, 42(1), January 2015:89-112.

White, P., I.R. Badu and P. Shrestha (2015). 'Achieving sustainable water supply through better institutions, design innovations and Water Safety Plans - the experience from far west Nepal.', Journal of Water, Sanitation and Hygiene for Development, 5(4):625-631.

Wilson, G. (2007) 'Knowledge, innovation and re-inventing technical assistance for development', Progress in Development Studies 7(3):183-199. 